\title{
Formen des Klärens by Christian Erbacher
}

\author{
Tea Jankovic
}

\begin{abstract}
Erbacher, Christian (2015). Formen des Klärens: Literarisch-Philosophische Darstellungsmittel in Wittgensteins Schriften. Münster: mentis.
\end{abstract}

This book, the title of which I would translate as Forms of Elucidating, Literary-Philosophical Means of Presentation in Wittgenstein's Works, ${ }^{1}$ comprises and analyzes critically the most important phases of almost a hundred years of both English and Germanspeaking Wittgenstein scholarship on the form of Wittgenstein's literaryphilosophical presentation. Furthermore, Erbacher demonstrates a thorough first-hand knowledge of Wittgenstein's manuscripts and manner of work, while at the same time offering an elegantly understated interpretation of the Tractatus logicophilosophicus, as well as of later works. This interpretation takes into consideration both Wittgenstein's serious and intense ethical and aesthetic preoccupations, and his significant contributions to logic and philosophy of language. Despite its density, Erbacher's slender book of no more than 132 pages achieves a concise lucidity and thus performatively shows the unity of aestheticrhetorical form and philosophical content, as well as the ethical ideal of clarity at the core of Wittgenstein's concerns.

Erbacher emphasizes that Wittgenstein considered his work an "activity of elucidation" (TLP 4.112), and not a static body of doctrine. His main medium was conversation, not a monologue - he had a genuine wish to be understood, to show and actualize for his students (and readers) his manner of practicing philosophy. One of the main theses of the book is that this "showing" is achieved primarily by means of presentation of his philosophy, of its literary form. Erbacher joins the ranks of those Wittgenstein interpreters (like Gottfried Gabriel), who view the literary form of his work as deliberate

\footnotetext{
1 "Darstellung" is often translated as "representation", however the latter term does not do justice to Wittgenstein's literary aspirations and anti-representationalist language philosophy. I thank Gino Margani for discussions on this topic.
} 
and essential to the understanding of its content (p. 9). By contrast, according to Erbacher, the first wave of Wittgenstein scholarship, including the Tractatus reception by Russell, Moore and later the Vienna Circle, regarded its style as incidental and due to Wittgenstein's personal eccentricities. On this view, which persists today in the works of Hacker and Glock, it is up to the exegete to painstakingly recreate the premiseand-conclusion structures of Wittgenstein's writings, against the grain of his "obscure" and "idiosyncratic" style (pp. 13-16). Such a reading in turn obscures the aesthetic aspiration Wittgenstein invested in his philosophical work, which is most obvious in his remark that the Tractatus should be viewed as philosophical as well as literary ${ }^{2}$ and his calling the Philosophical Investigations "an album" (PI, foreword), but also in his well-known pronouncement that "philosophy ought only be written as a poetic composition" (CV, 24).

Erbacher reviews Alois Pichler's Vom Buch zum Album (2002) on the history of the Investigations and its deliberate dialogical and album-like aesthetic qualities. Furthermore, thanks to his acquaintance with Wittgenstein's manuscripts, he places Wittgenstein's often quoted pronouncement that philosophy ought to be composed as poetry ("Philosophie dürfte man eigentlich nur dicbten") in the context of his recurrent evocation of a search for "the redeeming word" ("das erlösende Wort" $)^{3}$, the word that would satisfy philosophical questions and thus end them (p. 21-23). Erbacher emphasizes that it is precisely a linguistic expression that achieves this, the redeeming word, and he reads it in the context of its immediately preceding note on poetically composed philosophy. On this reading, the redeeming word, which puts an end to philosophical problems by dissolving them ("erlösen", "to redeem" in German contains the root "lösen", "to solve"), is the perfected poetic expression.

Erbacher postulates "philosophical poeticity" in Wittgenstein's work, defining it in terms comparable to Roman Jakobson's conception of the poetic function (p. 31 ff.). Jakobson introduces the concept of "plurifunctionality" of language. Rather than being limited to its referential function (or to use Wittgenstein's terms, truth-functionality), language has various other emotive, imperative, metalinguistic etc. functions, including the poetic function. Jakobson (for instance 1979, 79; quoted in Erbacher, p. 31) characterizes "poeticity" as the linguistic quality of not referring to any particular object, but to language itself. This abstract definition is especially productive when analyzing poetic texts that are not literary in the

\footnotetext{
${ }^{2}$ In a letter to Ludwig von Ficker, 7.10.1919 (Wittgenstein 2011).

${ }^{3}$ Noted in Ms 115, 30 [2]-[4] in immediate succession. I join James C. Klagge (2010, 125) in translating "das erlösende Wort" literally, as "the redeeming word", as opposed to "the key word" in Anscombe's translation.
} 
institutionalized sense, such as Wittgenstein's philosophical works.

In Part II, Erbacher reads the Tractatus in terms of the search for "the redeeming word", in the sense of the aspiration to philosophical poeticity, of language showing itself. However, he first summarizes the main strands of competing interpretations of this work. On the one hand, he (perhaps too) amply quotes the influential positivist exegetes who view the style in which the work was written as a "formidable obstacle" rather than a worthy object of investigation. Consequently, he summarizes "the resolute reading" introduced by Cora Diamond and James Conant. In contrast to the positivists, resolute readers pay attention to the form of the Tractatus.

Diamond and Conant (2004, 6568) identify an "interpretatory frame", originally consisting of the foreword of the Tractatus, and its ending, with special focus on 6.54, later adding other sentences of the Tractatus to the frame. Conant approaches Wittgenstein's work with the stance that its form is not merely ornamental, but that its "mode of presentation bears a profoundly intimate relation to its philosophical ambition" (2002, 377). Despite his sympathy for the resolute reading, Erbacher criticizes it, as well, on the charge of arbitrarily assigning propositions of the Tractatus to "the frame" or to the main body of work, and of sacrificing the content of Wittgenstein's actual insights in the

\footnotetext{
${ }^{4}$ Here he follows Hacker's critique (Hacker 2000, 357).

${ }^{5}$ Cf. Wittgenstein's letter to von Ficker, 20.10.1919 (Wittgenstein 2011, 35).
}

work, such as the general form of the proposition, to a content-negating, "deconstructive" attention to form (p. $55 f.){ }^{4}$

As an alternative to both the positivist and the resolute reading, Erbacher draws attention to Wittgenstein's own characterization of his work as "ethical" and to the many propositions within the Tractatus that serve ethical aims (56 ff.). ${ }^{5}$ For this, he draws on Janik and Toulmin's Wittgenstein's Vienna (1973), which places Wittgenstein's ideas in the until then largely overlooked context - of the cultural, artistic and political discussions of Viennese intellectual life Wittgenstein was very much rooted in. The journalist Karl Kraus, whom Wittgenstein explicitly named as one of his greatest influences, was an opponent of scientism. With Loos, Kraus propagated the idea that ethics is not exhaustively definable via natural science and that it is "shown" in the way life is lived, primarily - in the style of speaking and writing. Kraus and Loos speak - not of ethics being a matter of taste - but of an "ethics of clarity" that is shown aesthetically, stylistically (p. 58 f.). Therefore, the "philosophical poeticity" Erbacher is introducing in the analysis of Wittgenstein's work as a whole, is not reducible to an intransitive, merely self-reflective aestheticism, but the "redeeming word" has an ethical dimension, and clarity as its object. 
In his interpretation of the Tractatus, Erbacher finds its literary quality in the rhetorical style of the work. $\mathrm{He}$ identifies rhetoric as protostructuralist analysis, in line with Jakobson's frequent focus on rhetorical tropes (p. 65 ff.). For instance, in accordance with the principle of the rhetorical device of adiectio, or "repetition", Erbacher presents us an intricate network of interlinked propositions in the Tractatus, connected by the repetition of key words or phrases. Thus, rhetoric provides him with conceptual resources for determining which propositions belong to the frame, and which to the main body of the work. In contrast to the resolute reading, Erbacher identifies not one, but two frames. First an outermost frame, based on the repetition of the call to silence in the foreword as well as in 7, as well as an inner frame, based on the repeated reader address in the foreword and in 6.54, and within these two frames a gradatio (culmination) of mutually interconnected smaller steps linking 1 and 6 . Whereas 3, which introduces the logical picture, is the only unpaired colon of the work acting as an axis or a mirror and mediating between sentences on the world (1-2) and on language (4-6). The climax of the gradatio is 6 , the general form of the proposition. Erbacher presents his findings in a clarifying illustration, showing the graphic form of the work (much in the same expressive way a poem's graphic form can be said to express its meaning) (p. 69).

Erbacher is thus able to preserve
Wittgenstein's substantial contribution to logic and philosophy of language by showing that the aesthetic form of the work highlights precisely 6 , and not 6.54 as the resolute reading assumes. The outermost frames do not serve merely as reading guidelines (as in the resolute reading), but performatively show the limits of language (p. 75). Furthermore, Erbacher shows that Wittgenstein's presentation of the picture theory of language relies on the notion of mathematical projection (Abbildung), but also on poetic images (spracbliche Bilder), namely rhetorical tropes such as metaphors and metonymies (p. 81 ff.). The object of philosophical clarity is achieved, not solely by means of exact logical analysis, but by a rhetorically benevolent dialogical engagement of the reader that begins in the Tractatus's foreword, and that balances the virtues of brevitas (concision) and perspicuitas (comprehensibility) throughout the work (p. 94 ff.).

Part III studies Wittgenstein's Nacblass between 1929 and 1951. It is precisely this diachronic investigation of his later works that reveals the activity aspect of Wittgenstein's work: it is an activity of elucidating. In contrast to the Tractatus, where the smallest units of language were identified to be elemental propositions, and Jakobson's poeticity criterion was applied to repetition of such elemental units (e.g. "we must be silent"), Wittgenstein's later writings are structured through a repetition of whole grammatical structures, which have a similar function in the text (in 
keeping with Wittgenstein's own shift of focus from the propositional form to grammar). As examples of these, Erbacher focuses on the grammatical structures he calls "case study" (Fallbeschreibung) as developed by Wittgenstein until 1932/33 (p. 117 ff.), and the diachronic development of Wittgenstein's punctuation practice in this early period of the "late Wittgenstein" (p. 126). By thus shedding light on one phase in the long course of the becoming of the Philosophical Investigations, Erbacher reveals Wittgenstein's very deliberate, at times painstaking search for the redeeming word.

In terms of criticism, Erbacher's reception of the resolute reading as content-negating, or "deconstructive", does not match its proponents' self-understanding. For, resolute readers see their position as affirming Wittgenstein's own concern to satisfy, not annihilate, philosophical questions (Diamond 2011, 240 ff.). Their reading goes hand in hand with Wittgenstein's persistent antirepresentationalism, and what they are after to "deconstruct" is not the content of Wittgenstein's philosophical insights, but mistakenly reifying interpretations of these very insights.

Furthermore, from the point of view of literary studies, Erbacher's introduction of rhetoric as a means of elucidation is curiously optimistic. It is presented as straight-forwardly and transparently transporting the intended philosophical meaning. By contrast, rhetoric is traditionally viewed with mistrust as a device of persuasion by means of deft concealment of logical relations. ${ }^{6}$ In addition, Erbacher does not devote much attention to one of Jakobson's central theses - that poeticity implies a plurality of possible interpretations. ${ }^{7}$ Erbacher does concede that his poetic-philosophical reading of the Tractatus is one possibility among many, and emphasizes the scholar's power of judgment in choosing the appropriate conceptual frameworks to address both the aesthetic and the epistemological aspirations of the text (p. 64 f.). However, he does not in detail reflect on how the ambiguity of meaning intrinsic to Jakobson's understanding of the poetic function relates to the, otherwise strongly argued, isomorphy of poetic form and philosophical content in Wittgenstein's work.

However, it is a strength of the book that it raises further questions and opens new vistas for transdisciplinary engagement with Wittgenstein's work. From the perspective of literary studies, it is exciting to analyze Wittgenstein's philosophical work with methods of literary criticism.

\footnotetext{
${ }^{6}$ Besides Plato's well-known rejection of the Sophists' rhetorics, cf. also e.g. Paul de Man's rhetorical, and at the same time deconstructive reading of the Tractatus in de Man (1979).

${ }^{7}$ Cf. Jakobson 1981, 42. This and the previous point (fn. 6) I owe to discussions with the participants of the Doctoral Colloquium in Literary Studies lead by Prof. Thomas Grob at the University of Basel, in the Autumn Term 2015.
} 
Even though Erbacher's analysis in terms of classical rhetoric does not exhaust the poetic potential of Wittgenstein's text, it is a convincing demonstration of just this potential, and invites further investigations into the synergy of poetic and logical form. ${ }^{8}$

$$
\begin{array}{r}
\text { University of Fribourg, Switzerland } \\
\text { tea.jankovic @ unifr.ch }
\end{array}
$$

\section{References}

Conant, J., 2002. "The Method of the

Tractatus". In: E. H. Reck, ed., From Frege to Wittgenstein: Perspectives on Early Analytic Philosophy. Oxford: Oxford University Press.

de Man, P., 1979. Allegories of Reading. New Haven: Yale University Press.

Diamond, C. \& Conant, J., 2004. "On Reading the Tractatus Resolutely". In: Kölbel, M. and Weiss, B., eds., The Lasting Significance of Wittgenstein's Philosophy. London: Routledge.

Diamond, C. 2011. "The Tractatus and the Limits of Sense". In: O. Kuusela and M. McGinn, eds., The Oxford Handbook of Wittgenstein. Oxford: Oxford University Press.
Hacker, P. M. S., 2000. "Was He Trying to Whistle It?". In: Crary, A. and Read, R., eds., The New Wittgenstein. London: Routledge.

Jakobson, R., 1979. Poetik - Ausgewäblte Aufsätze 1921-1971. Frankfurt a.M.: Suhrkamp.

Jakobson, R., 1981. Poetry of Grammar and Grammar of Poetry. Hague: Mouton.

Janik, A. \& Toulmin, S., 1973. Wittgenstein's Vienna. New York: Simon and Shuster.

Klagge, J. C. 2010. Wittgenstein in Exile. Cambridge, M.A.: MIT Press.

Pichler, A., 2002. Wittgensteins Philosophische Untersuchungen: vom Buch zum Album. Amsterdam: Rodopi.

Wittgenstein, L., 1922. Tractatus Logicophilosophicus. Trans. C.K. Ogden. London: Kegan Paul. TLP

Wittgenstein, L., 1958. Philosophical Investigations, transl. G.E.M. Anscombe. Oxford: Blackwell. PI

Wittgenstein, L., 1998. Culture and Value, rev. ed., ed. G. H. von Wright, transl. P. Winch. Oxford: Blackwell. CV

Wittgenstein, L., 2011. GesamtbriefwechselInnsbrucker elektronische Ausgabe $\left(2^{\text {nd }}\right.$ release). M. Seekircher, B. McGuinness and A. Unterkircher, eds. Charlottesville: InteLex.

\footnotetext{
${ }^{8}$ References amended in this version Apr. 27, 2020, by editor (first publication June 27, 2016).
} 